\title{
A New Residential Load Management System in Presence of Variable Load and Market Price
}

\author{
M. Rahmani ${ }^{1}$ \\ Power Electrical Engineering Department, Amirkabir University of Technology, Tehran, Iran ${ }^{1}$
}

\begin{abstract}
Modern smart grids are a combination of advanced structures to make the energy supply to the costumers more reliable and flexible. Variable pricing can affect this process and usage of the smart home appliances. The storage systems in variable pricing environment can help the customers to take advantage of varying in tariffs to optimize their incomes and outcomes. The basic structure of using distributed storage systems in a single home can be modified to optimize its benefits. In this paper, a comparison between the old configuration of smart homes having storage systems and a modified storage structure is done. First, load commitment problem for different users is being performed. Afterwards, the storage system has been condensed for the user to show the effectiveness of the proposed method. At the end, to compensate the additional costs to the customer, the pretending acting method is introduced.
\end{abstract}

Keywords: Smart Home, Demand Side Management, Electric Vehicle, Electricity Market, Load Management.

\section{INTRODUCTION}

Distribution level is not as the same state as it was in the past years. Besides the protection issues, energy consumption in distribution level and methods for its management have been studied in recent years [1-3]. Micro grids and smart grids are the outcomes of these studies which try to solve aforementioned issues in the distribution network [4]. Monitoring and protection of the mechanical parts of the system is not discussed here but novel structural health monitoring (SHM) methods can be employed to do structural analysis and health monitoring of these parts [5-7]. Another matter of concern is the islanding detection which its consequences can affect the dynamic and static behaviour of the system [8].

Demand side management (DSM) as one of the most common ways in energy management has been focused by many researchers to find out its advantages and disadvantages [9]. DSM tries to change the habits of the customers in consuming electrical energy. The effect of DSM has been seen from different points of view. It is possible to utilize DSM to maximize the flexibility and efficiency of the grid and reducing the electricity consumption at the same time [10].

Storage systems are one of the appliances, which can help make the power supply system more flexible. Storage systems have been tested to affect the price values in competitive markets [11-12]. The storage systems not only are able to be part of pricing process but also can be used in demand side management programs [13]. DSM can be processed through different programs. Demand response as one of them [14] helped a lot to reduce the residence active power demand by receiving feedbacks from the customer's side. One way to access the demand response, is using load commitment programs to manage the controllable loads.
In the context of the energy crisis, the development of electric vehicles (EVs) has gained the attention of many countries [15-16]. EVs are one of the storage system members, which are effective in DSM programs. They can be used in peak shaving [2] and minimizing the system's loss by controlling the charging and discharging processes [17]. The major problem with EVs is in their charging process. Increased power losses is one of the problems which may happen with uncontrolled and random charging process [18]. Despite the savings they may have due to difference in energy prices in different hours and peak shaving, peak shifting is one other problem in association with the EVs. In some cases, EVs change the peak hour from the hours near midnight to the mid-day hours. This change in demand may be favourable by the customer to save additional costs, but it is not maybe favourable by the distribution companies.

Batteries as other members of the storage systems family are effective in energy management by not having any constraints but their capacity, charging, and discharging periods. The traditional structure design with storage systems in distribution level in most situations has focused on outage problems and its costs [19], energy supply, and voltage regulation [20], but its effect on peak to average ratio (PAR) has been missed.

This paper introduces a new method in charging and discharging process to minimize PAR in domestic loads and customer's total cost at the same time. The three steps price values encourage the customer to optimize its loads and storage systems.

In this paper, in chapter 2 the load commitment problem and its goals are introduced and the required mathematical equations represented. Chapter 3 discusses about the old structure and replaces the old storage system placement structure with a new and more advantageous one, and in 
Vol. 5, Issue 2, February 2017

chapter 4 , a proper case study has been used to prove the validity of the proposed method.

\section{LOAD COMMITMENT PRIORITIES}

\section{A. Variable Pricing Strategies}

Power market in modern power systems' structure has an important role in transmission level. Generation side competitions to maximize the economical benefits make the power systems to face variations in prices and power curves [21]. Although this competition can be affected by the transmission level harmonics by increasing the local marginal prices [22], its effect has been ignored in this paper. This variation in upper level results in distortion in costs of retailers in lower level. Thereupon, retailers change the electricity price pattern in distribution level to compensate these undesirable costs.

There are almost two main price profiles: constant and variable price profiles. In constant price profile, the retailers are motivated to set a constant value to reimburse the different costs in a complete day-ahead market. This policy seems not to be a preferred strategy by the retailers and distributers due to not being motivating enough in a competitive market and not having enough benefits for the distribution companies.

On the other hand, variable pricing in distribution level is more acceptable by the costumers and distributers. By putting some regulations, distributers can issue enough motivations to decline the power consumption in peak hours and even intensify the customers to shift it into offpeak hours to make the power curve smoother.

Costumers in smart grids may face different tariffs for their consumption, which are forced by upper level to the lower level companies. The idea of variable tariffs is based on equilibrium between generation and demand and describes how any jump in load consumption can increase the price rapidly. In peak demand hours, it would be reasonable to expect a rise in electricity price. Furthermore, the power market players in upper level can change the price by variation in their offers and bids.

The tariff profile in modern distribution levels follows a variable pattern. Some papers have been studied the methods for electricity pricing in distribution level for load management programs [23]. Among various pricing patterns, three steps pattern having three main zones of peak, mid-peak, and off-peak periods is the most common one. In this pattern, the customer is willingly interested in shifting its demand into the off-peak or mid-peak hours. Fig. 1 represents this method of energy pricing and compares it with constant and two steps patters graphically. Distributers can follow any other patters to intensify their customers.

\section{B. Smart Home Load Commitment}

Load commitment in smart homes has important impacts on basic characteristics of the distribution level. As it is mentioned before, equivalence between the cost and load profile should replace the whole idea of economical benefits by solving the load commitment problem. A smart home is considered as a unity with an electrical identity acting as a unique stable body having the ability of

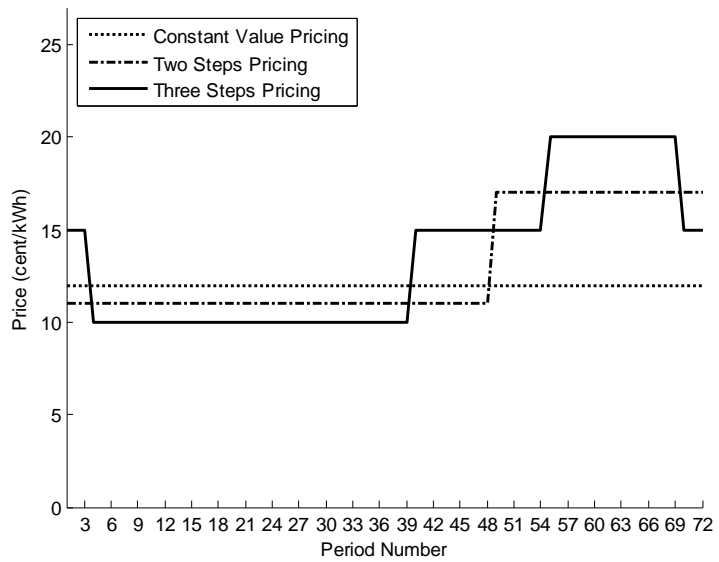

Fig. 1. The three usual methods of pricing

consumption which can act as an intelligent agent [24]. These abilities require various infrastructures as are presented in Fig. 2. Loads in smart homes are categorized in two main groups. Controllable loads (CL) and noncontrollable loads (NCL) to represent the controllability of the costumer's consumption at the same time. CL's often are the largest consumers of the active power in a smart home and may cause undesirable demand in peak hours. The goal for every load commitment problem is to minimize the distance between the demand amount in peak hours and off-peak hours. The lesser PAR results in better consumption programming.

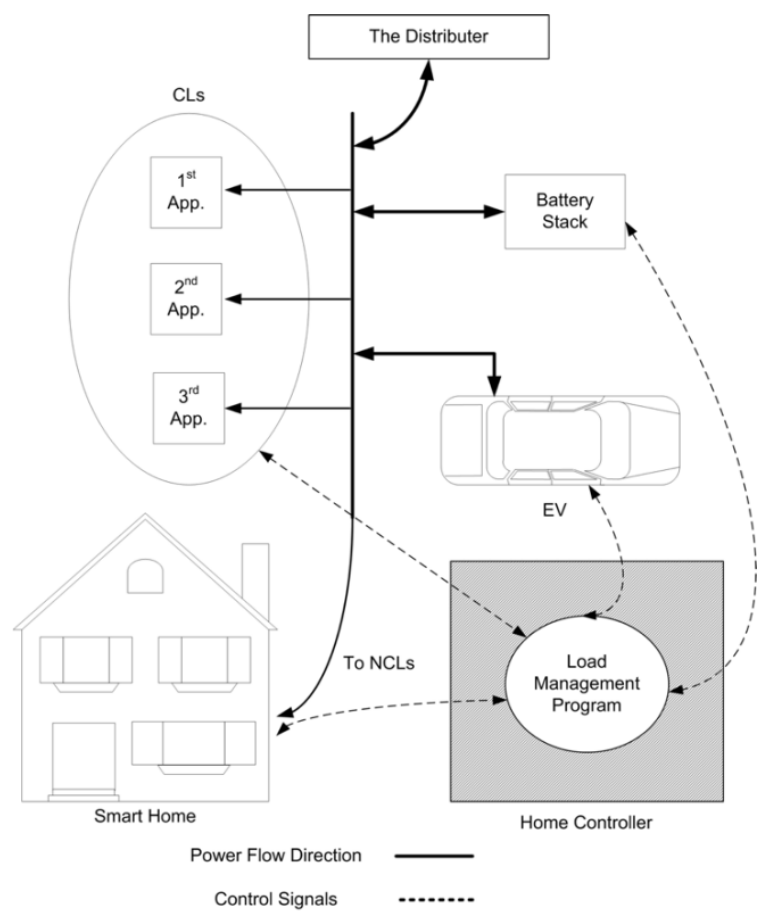

Fig. 2. Smart home appliances and characteristics 


\section{International Journal of Innovative Research in Electrical, Electronics, Instrumentation and Control Engineering}

\section{ISO 3297:2007 Certified}

Vol. 5, Issue 2, February 2017

CL's vary from house to house by changing in equipment consuming the active power. Each smart home may have different numbers and types of CL's, which may change the outcome of the load commitment problem. The constraints on duration and the time of using the equipment are the parameters influencing the outcome of the problem [2].

Solving the load commitment problem requires the knowledge on the CL's and NCL's types [25]. Accordingly, load curve can be classified into two main curves of base load curve (BLC) and controllable load curve (CLC). Different placement of the CLs makes the CLC. In addition, BLC is made by the sum of NCL's in a full day-ahead to make a base load profile, which may vary in different hours of the day. The CLC and BLC combinations make the smart home power curve. The load commitment problem result can be found by solving the Eq. 1 [2].

$$
\min \operatorname{Cost}=\sum \text { price } \times\left(E_{N C L}+E_{C L}\right)
$$

Where $\mathrm{E}_{\mathrm{NCL}}$ and $\mathrm{E}_{\mathrm{CL}}$ are, the energy consumed by the noncontrollable and controllable loads respectively, and price is the tariff represented to the costumer by the distributors. Since the working point of the load commitment problem does not affect the multiplication of $\mathrm{E}_{\mathrm{NCL}}$ and price, solving the Eq. 2 can issue the proper placement of the CL's during the day to find the position having minimum cost and lesser PAR.

$$
\min \text { Cost }=\sum \text { price } \times E_{C L}
$$

Storage systems can change the results of the load commitment problem if they are processed before the CL's. Storage systems have important role in solving load commitment problems. Despite uninterruptable power supply (UPS), which is functional in the case of any interruption in supplying the electricity by the power distribution grid, EVs and batteries are utilizable in the case of encouraging the costumer to take participate in the load commitment program.

The process of storage systems, loads, and generation in a smart home can affect the load commitment result. The way they come together in solving the load commitment problem can change its outcome. Since the smart grids are supposed to have a proper PAR and more customers are satisfied to join it. The basic structure of solving load commitment problem is represented in Fig.3.

Loads and DGs are the same type. They are consumers of active power one in positive way and the other in negative way. In addition, they can be classified as one body named generation/consumption unit (GCU) in load commitment problem. The outcome of GCU makes the total load curve. Because it is desirable by the customer to have the generation unit into the circuit all the time, it can be classified as a negative NCL.

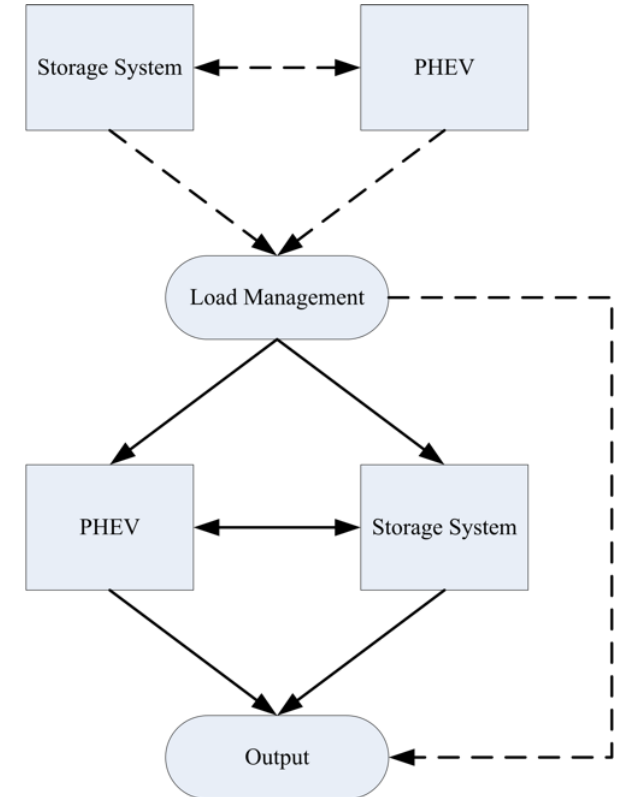

Fig. 3. Smart home appliances and characteristics

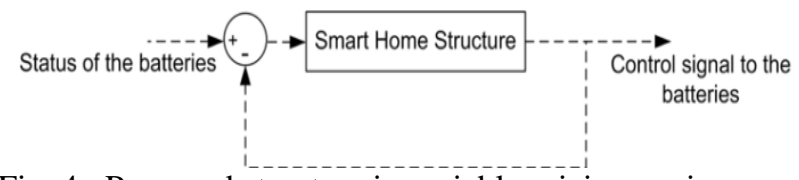

Fig. 4. Proposed structure in variable pricing environment

On the other hand, EV and batteries are storage system members. They both make the load curve flexible. Despite the batteries, EV is forced by the user to get charged before starting the outdoor operation. Therefore, home controller (HC) puts EV in a prior position compared to the batteries.

Moreover, to gain the best results in PAR and cost, a compromise should place between GCU and storage system. Although, no constraint can limit the storage system if it wants to act independently as a prior to GCU, the storage system may draw a limit for the GCU members to take part in the load commitment program by tightening them into the upper limit of active power supply described in this paper as congestion.

The congestion limit can be introduced by the distribution company to the customer to ensure the eligibility of the installed infrastructure in distribution level and avoid any technical problem [2].

\section{STRUCTURE RECONFIGURATION}

Storage systems can store the electrical energy under circumstances and inject it into the grid in the time of need. Storage systems show their importance in the case they face variable tariffs in a day-ahead market. Saving energy in off-peak hours and injecting it into the grid in peak hours is the main role of these devices in a smart home.

In smart homes, storage systems make load profile more flexible by putting the customers' convenience and 


\section{International Journal of Innovative Research in Electrical, Electronics, Instrumentation and Control Engineering}

\section{ISO 3297:2007 Certified}

Vol. 5, Issue 2, February 2017

benefits into account, but they can make serious problems by encouraging the users to concentrate their electricity demand in the times that the electricity price has lower value than other hours. This makes the load profile to face another peak value in currently off-peak hours.

An EV, for outdoor operation, is functional in some periods of the day, which user regularly represents it to the load commitment program. In the other periods, user can take advantage of EV storage battery. Although EVs are the appliances, which may help to get through the peak hours by injecting the stored power in their batteries to the home network, they still can make currently off-peak hours one of the main peak hours of the day. Consideration of the EV users makes it difficult to reconfigure the structure that an $\mathrm{EV}$ is present.

Batteries as the other storage system members can have important roles in peak clipping or load shifting. Due to not having any constraint forced by the user, despite of their size and type, charging and discharging the batteries is possible in any circumstance in their boundaries.

Working of EVs and batteries together as the storage systems may shift the load peak value into non-peak price hours and thus results in preferable PAR. The goal of this paper is to control PAR considering the benefits of the customer.

The new structure reconfiguration suggests that two new sub-batteries replace the old battery stack. The batteries charge and discharge status is a function of the load curve PAR. A negative feedback from the PAR status makes the batteries reliable in this formation. The proposed method is demonstrated in Fig. 4.

To show the validity of the proposed method, two battery stacks having half capacity of the original battery are replaced the old one. The two stacks electrically are in parallel with each other and perform in series. The first stack acts after process of EV battery. By finding the peak values of the load curve, the first stack connects to the program and results in lower PAR. The second stack is processed right after the first stack by reducing the load values in the times even far from peak price hours. By finding the peak load values for discharging and minimum values for charging process, the two stacks are about to make the load curve smoother.

Though the customer's total income surely is affected by this method, reducing the PAR amount has its costs for the distributers. This cost can make the customers to exit the load commitment program. To ignore it, the distributors should replace a new method to consider the both sides' benefits.

This paper suggests using the method of pretending/acting (PA) in customer's payments. In this method, the costs for costumer's energy consumption are calculated in the most profitable working point found by HC. This working point, if approved, may be a good point for the customer, but a bad one for the distributers.

The difference between the normal $\mathrm{HC}$ working point and the new one makes a gap in customer's cost, which will be paid by the distributer who is supplying the smart home. This cost is for keeping PAR in a normal range and is claimed to be rent of the smart home storage system.

\section{IV.CASE STUDY}

To show the effectiveness of the proposed method, a case study has been made. An example smart home has been considered and its loads have been classified into CL's and NCL's. The number of CLs is up to the house owner and in here is assumed as three. The characterizations of the smart home CL's are represented in Table 1. on the other hand, NCL's are the combinations of different and usually smaller loads than CL's. The distribution of NCL's in a day-ahead plan makes the smart home BLC, which is represented in Fig. 5.

\section{TABLE I CONTROLLABLE LOADS CHARACTERISTICS}

\begin{tabular}{ccccc}
\hline $\begin{array}{c}\text { Applianc } \\
\text { e } \\
\text { Number }\end{array}$ & $\begin{array}{c}\text { Active } \\
\text { Power } \\
\text { Demand } \\
\text { (kW) }\end{array}$ & $\begin{array}{c}\text { Duratio } \\
\text { n of } \\
\text { Operati } \\
\text { on }\end{array}$ & $\begin{array}{c}\text { Lower } \\
\text { Constr } \\
\text { aint }\end{array}$ & $\begin{array}{c}\text { Higher } \\
\text { Constr } \\
\text { aint }\end{array}$ \\
\hline $\mathbf{1}$ & 1 & 4 & 1 & 72 \\
$\mathbf{2}$ & 1.4 & 3 & 58 & 70 \\
$\mathbf{3}$ & 1.2 & 3 & 25 & 60 \\
\hline
\end{tabular}

TABLE II STORAGE CHARACTERISTICS

\begin{tabular}{lll}
\hline Storage Type & EV & Battery \\
\hline Capacity $(\mathrm{kWh})$ & 8.8 & 8.8 \\
Daily Power Consumption $(\mathrm{kWh})$ & 1.6 & - \\
Charging Efficiency & 0.88 & 0.88 \\
Discharging Efficiency & 0.88 & 0.88 \\
Charging Periods & 9 & 9 \\
Time to Discharge & 30 & - \\
Time to Charge & 45 & - \\
\hline
\end{tabular}

Using Table II, to describe the storage system's characteristics, the load commitment result considering EV battery into account is shown in Fig. 6 for 20 minutes steps.EV battery satisfies its constraints by charging in low price hours and discharging in high price hours.

By adding the traditional battery stack to the system, HC contributes the loads, EV, and the battery in a way to maximize the profit of the owner. As it is presented in Fig. 7 , choosing a battery having the capacity near the battery size of the EV smoothens the load curve, but shifts the peak value.

Based on the proposed method, two battery stacks having the half capacity of the old configuration battery have been used to reduce the PAR variation in 24-hours day. Adding the first stack changes the load curve so that it reduces the peak load value and increases the minimum. As the result, PAR lessens to 1.66 that is almost $6 \%$ better than the old configuration. On the other hand, the customer's payment increases 15 cents to 326 cents for a 24-hours day. 


\section{International Journal of Innovative Research in Electrical, Electronics, Instrumentation and Control Engineering}

\section{ISO 3297:2007 Certified}

Vol. 5, Issue 2, February 2017

The second stack maintains the load commitment process by $6 \%$ and brings the PAR down to 1.57 . The payment still has an increasing to 331 cents. Figs. 8 and 9 demonstrate the two stacks effects on the load curve of the smart home.

In the foretold figures, the customer's total income has reduced so that it can improve the PAR characteristics. Though this additional cost as the storage system is rental and will be paid by the distributer for avoiding the smart grid maintenance costs, they can be omitted compared with over $10 \%$ reduction in PAR of power consumption.

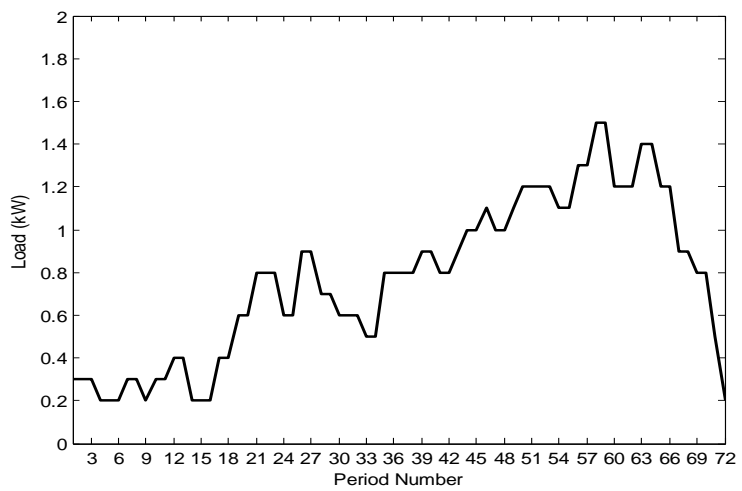

Fig. 5. An example base load curve for a load commitment problem

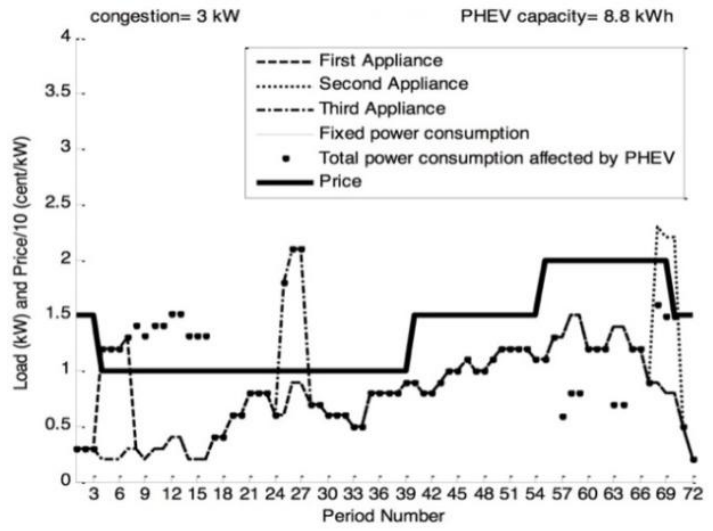

Fig. 6. Load commitment result in presence of EV

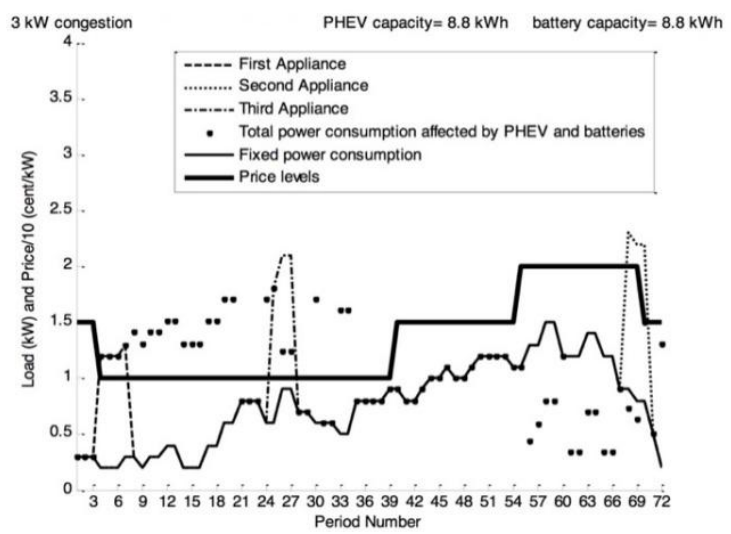

Fig. 7. Load commitment result having the same size battery storage system and EV battery

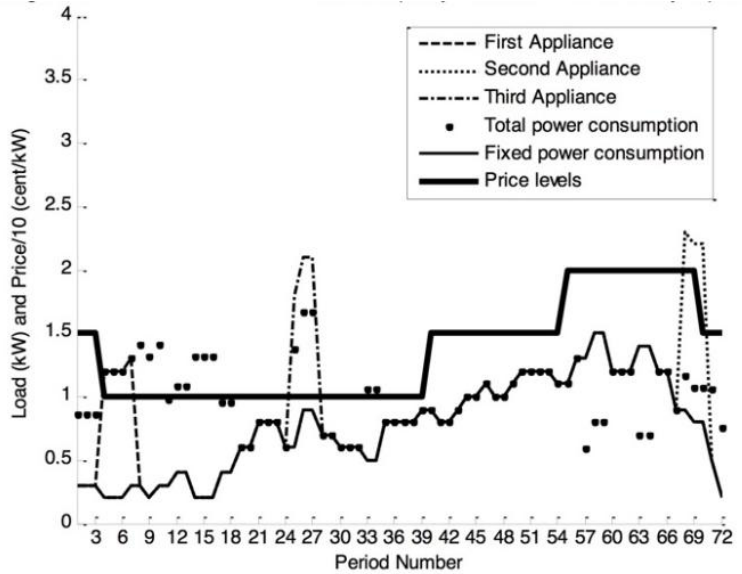

Fig. 8. Load commitment result by entering the first stack

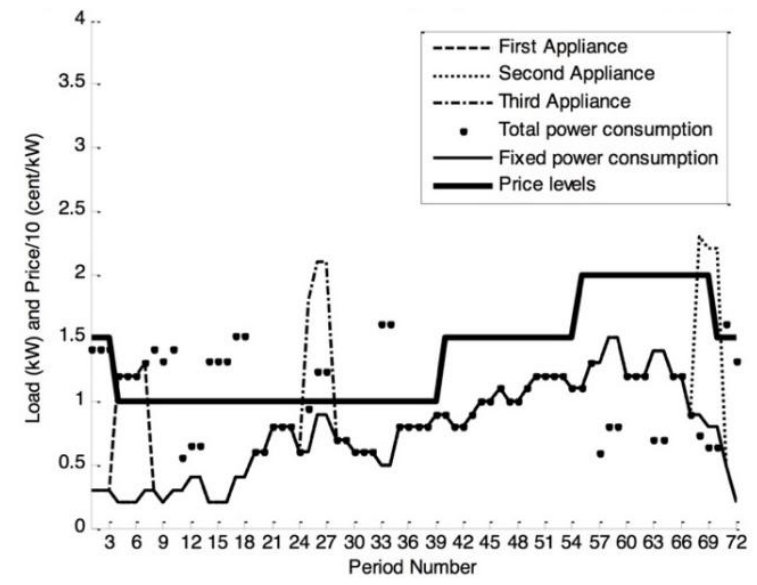

Fig. 9. Load commitment result by entering the second stack

\section{CONCLUSION}

In this paper, the old structure of using storage system in smart homes is discussed. The most important critic on the old structure is about its role in peak shifting instead of peak clipping in residential areas. Although EV and battery as storage systems are used to maximize the customer's benefits, using them to minimize the PAR is the other issue that has been focused in this paper. To lessen the PAR ratio, the old structure of one big battery stack has been revised into two battery stacks having the half capacity of the old one. By changing the algorithm to the one in which EV is responsible for financial benefits and battery is for PAR, their combination changed the load curve of the smart home to be more smooth and desirable by the electricity distributer having the minimum cost for the customer.

\section{ACKNOWLEDGMENT}

The heading of the Acknowledgment section and the References section must not be numbered.

Causal Productions wishes to acknowledge Michael Shell and other contributors for developing and maintaining the 


\section{ISO 3297:2007 Certified}

Vol. 5, Issue 2, February 2017

IEEE LaTeX style files which have been used in the preparation of this template.

\section{REFERENCES}

[1] R. Rankin, P. G. Rousseau, and M. van Eldik, "Demand side management for commercial buildings using an inline heat pump water heating methodology," Energy conversion and management, vol. 45, pp. 1553-1563, 2004.

[2] M. Rastegar, M. Fotuhi-Firuzabad, and F. Aminifar, "Load commitment in a smart home," Applied Energy, 2012.

[3] M. Masoum, P. Moses, and S. Deilami, "Load management in smart grids considering harmonic distortion and transformer derating," in Innovative Smart Grid Technologies (ISGT), 2010, 2010, pp. 1-7

4] V. Sarfi, I. Niazazari, and H. Livani, "Multiobjective fireworks optimization framework for economic emission dispatch in microgrids." North American Power Symposium (NAPS), 2016, pp. 1-6, Nov. 2016

[5] Khalili A., Jha R., Samaratunga D. "Spectrally Formulated UserDefined Element in Conventional Finite Element Environment for Wave Motion Analysis in 2-D Composite Structures." European Journal of Computational Mechanics, November 11, 2016, DOI: 10.1080/17797179.2016.1253364.

[6] Khalili A., Samaratunga D., Jha R., Lacy T. E., Gopalakrishnan S "WSFE-based User-Defined Elements in ABAQUS for Modeling 2D Laminated Composites with Complex Features" 30th ASC Technical Conference, Michigan State University, East Lansing, MI, US, 28-30 September 2015.

[7] V. Sarfi, V. Hemmati, and M. M. Arabshahi. "Simulation of PTC devices as fault current limiters in power systems by finite element method." In High Voltage Engineering and Application (ICHVE), 2014 International Conference on, pp. 1-4. IEEE, 2014.

[8] H. Jouybari Moghaddam, S.H. Hosseinian, , B. Vahidi,M. Ghiasi Rad. "Smart Control Mode Selection for Proper Operation of Synchronous Distributed Generators”. In Smart Grids (ICSG), 2012 2nd Iranian Conference on pp. 1-4, IEEE, 2012.

[9] G. Strbac, "Demand side management: Benefits and challenges," Energy Policy, vol. 36, pp. 4419-4426, 2008.

[10] A. Pina, C. Silva, and P. Ferrão, "The impact of demand side management strategies in the penetration of renewable electricity," Energy, vol. 41, pp. 128-137, 2012.

[11] N. Prüggler, W. Prüggler, and F. Wirl, "Storage and Demand Side Management as power generator's strategic instruments to influence demand and prices," Energy, 2011.

[12] M. Masoomi, "Model development and load analysis of an offshore wind turbine," 2014.

[13] W. A. Qureshi, N. K. C. Nair, and M. M. Farid, "Impact of energy storage in buildings on electricity demand side management," Energy conversion and management, vol. 52, pp. 2110-2120, 2011.

14] P. Palensky and D. Dietrich, "Demand side management: Demand response, intelligent energy systems, and smart loads," Industrial Informatics, IEEE Transactions on, vol. 7, pp. 381-388, 2011.

[15] S. Jafarishiadeh, M. Ardebili, A. Nazari Marashi, "Investigation of pole and slot numbers in axial-flux pm bldc motors with singlelayer windings for electric vehicles," 24th Iranian Conference on Electrical Engineering (ICEE), pp. 1444-1448, 2016.

[16] Seyyedmahdi Jafari Shiadeh, Mohammad Ardebili, and Parvin Moamaei, "Three-dimensional finite-element-model investigation of axial-flux PM BLDC machines with similar pole and slot combination for electric vehicles", In: Proceedings of Power and Energy Conference, Illinois, pp. 1-4, 2015

[17] A. Masoum, S. Deilami, P. Moses, M. Masoum, and A. Abu-Siada, "Smart load management of plug-in electric vehicles in distribution and residential networks with charging stations for peak shaving and loss minimisation considering voltage regulation," Generation, Transmission \& Distribution, IET, vol. 5, pp. 877-888, 2011

[18] S. Deilami, A. S. Masoum, P. S. Moses, and M. A. S. Masoum, "Real-time coordination of plug-in electric vehicle charging in smart grids to minimize power losses and improve voltage profile," Smart Grid, IEEE Transactions on, vol. 2, pp. 456-467, 2011.
[19] J. M. Gantz, S. M. Amin, and A. M. Giacomoni, "Optimal mix and placement of energy storage systems in power distribution networks for reduced outage costs," in Energy Conversion Congress and Exposition (ECCE), 2012 IEEE, 2012, pp. 2447-2453.

[20] A. K. Barnes, J. C. Balda, A. Escobar-Mejia, and S. O. Geurin, "Placement of energy storage coordinated with smart PV inverters," in Innovative Smart Grid Technologies (ISGT), 2012 IEEE PES, 2012, pp. 1-7.

[21] F. Gao, X. Guan, X. R. Cao, and A. Papalexopoulos, "Forecasting power market clearing price and quantity using a neural network method," in Power Engineering Society Summer Meeting, 2000. IEEE, 2000, pp. 2183-2188.

22] H. Norouzi, S. Abedi, R. Jamalzadeh, M. Ghiasi Rad, S.H Hosseinian. "Modeling and investigation of harmonic losses in optimal power flow and power system locational marginal pricing." Energy Journal, Science Direct, P-68 (2014) 140-147

[23] K. Lo, J. McDonald, and T. Le, "Time-of-day electricity pricing incorporating elasticity for load management purposes," International Journal of Electrical Power \& Energy Systems, vol. 13, pp. 230-239, 1991.

[24] D. J. Cook, M. Youngblood, E. O. Heierman III, K. Gopalratnam, S. Rao, A. Litvin, and F. Khawaja, "MavHome: An agent-based smart home," in Pervasive Computing and Communications, 2003.(PerCom 2003). Proceedings of the First IEEE International Conference on, 2003, pp. 521-524.

[25] M. Masoomi, N. Shamsaei, X. Gao, S. M. Thompson, A. Elwany, L. Bian, N. Shamsaei, L. Bian, and A. Elwany, "Modeling, simulation and experimental validation of heat transfer during selective laser melting," in ASME 2015 International Mechanical Engineering Congress \& Exposition, 2015.

\section{BIOGRAPHY}

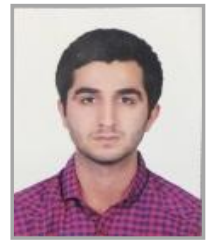

Mohyeddin Rahmani was born in 1988 in Ahvaz, Iran. He has received the B.Sc. \& M.Sc. degrees in power electrical engineering from Amirkabir University of Technology, Tehran, Iran, in 2011 and 2014. Presently, he is working as an automation specialist in a still company. His main interests of research are power market, renewable energies and load management. 